\title{
Vancomycin removal during low-flux and high-flux extended daily hemodialysis in critically ill septic patients
}

\author{
Nadezda Petejovaa ${ }^{a}$, Arnost Martinek ${ }^{\mathrm{a}}$, Jana Zahalkova ${ }^{\mathrm{b}, c}$, Jana Duricova ${ }^{\mathrm{d}}$, Hana Brozmanovad ${ }^{\mathrm{d}}$, Karel Urbaneke, \\ Milan Grundmann ${ }^{\text {, }}$, Ivana Kacirova ${ }^{\mathrm{d}}$
}

\begin{abstract}
Aims. To determine the extent of vancomycin removal and vancomycin pharmacokinetics in septic patients with AKI using daily hemodialysis with polysulphone high-flux and low-flux membrane.

Methods. Five patients received $6 \mathrm{~h}$ daily dialysis with low-flux polysulphone membrane, four patients with high-flux polysulphone membrane. Vancomycin was administered over the last hour of dialysis. The maintenance dose was adjusted based on pre-hemodialysis serum concentrations. Patients were followed up for two days.

Results. Median percentage of vancomycin removal by low-flux membrane dialysis was 17\% (8-38\%) and by high-flux membrane dialysis was 31\% (13-43\%). Vancomycin clearance was only moderately higher in high-flux membrane dialysis (median 3.01 L/h, range 2.34-3.5 L/h) compared to low-flux dialysis (median 2.48 L/h, range 0.53-5.68 L/h) in the first day of the study. About two-fold higher vancomycin clearance in high-flux dialysis (median $3.62 \mathrm{~L} / \mathrm{h}$, range 1.37$5.07 \mathrm{~L} / \mathrm{h}$ ) was observed on the second day of the study than low-flux dialysis (median $1.74 \mathrm{~L} / \mathrm{h}$, range $0.75-30.94 \mathrm{~L} / \mathrm{h}$ ). Conclusions. Both high-flux and low-flux membrane dialysis remove considerable amounts of vancomycin in critically ill septic patients with AKI. Application of vancomycin after each dialysis was required to maintain therapeutic concentrations.
\end{abstract}

Key words: acute kidney injury, hemodialysis, high-flux, low-flux, polysulphone membrane, sepsis, vancomycin

Received: August 21, 2011; Accepted with revision: January 3, 2012; Available online: January 30, 2012

http://dx.doi.org/10.5507/bp.2012.002

${ }^{a}$ Department of Internal Medicine, Faculty of Medicine, University of Ostrava and University Hospital Ostrava, Czech Republic ${ }^{b}$ Department of Internal Medicine, University Hospital Olomouc and Faculty of Medicine and Dentistry, Palacky University Olomouc 'Stredomoravska nemocnicni, Hospital Sternberk

${ }^{d}$ Department of Clinical Pharmacology, Faculty of Medicine, University of Ostrava and University Hospital Ostrava ${ }^{e}$ Department of Pharmacology, Faculty of Medicine and Dentistry, Palacky University Olomouc and University Hospital Olomouc Corresponding author: Nadezda Petejova, e-mail: petejova@seznam.cz

\section{INTRODUCTION}

Sepsis and septic shock are frequent causes of patients' admission to intensive care units: They often lead to multiple organ dysfunction syndrome with acute kidney injury (AKI) (ref. $\left.{ }^{1}\right)$.The incidence of AKI in septic patients is up to $51 \%$ and severe AKI requiring RRT (renal replacement therapy) occurs in $5 \%\left(\right.$ ref. $\left.^{2}\right)$. Indications for commencing RRT in sepsis - induced AKI are similar to other forms of AKI. Other indications for RRT are worsening azotemia, refractory volume overload, severe metabolic acidosis, uremic encephalopathy and severe electrolyte disarray ${ }^{3}$. In patients with sepsis, sustained oliguria or severe metabolic acidosis may be reason enough to start RRT as these patients often do not manifest signs of azotemia ${ }^{4}$. Two modalities of RRT are possible in the treatment of septic patients with AKI: either intermittent hemodialysis (IHD) or continual renal replacement therapy (CRRT). Recently, new RRT modalities like the hybrid method SLEDD (slow efficiency daily dialysis) and EDD (extended daily dialysis) have been used in the treatment of critically ill patients. Continual methods are preferred in haemodynamically unstable patients. However no dif- ference in patient survival has been found between CRRT or IHD modality in published studies 5 . Serious infections are common in critically ill patients and require rapid treatment to limit mortality and morbidity. The Surviving Sepsis Campaign recommends that intravenous antibiotics are begun within the first hour after diagnosis of severe sepsis and septic shock ${ }^{6}$.

Vancomycin is a part of empirical treatment in patients with the risk of infection caused by resistant gram-positive groups such as MRSA, coagulase-negative Staphylococci, Enterococcus faecium, or a therapy targeted at these pathogens. An AUC/MIC ratio of $\geq 400$, has been advocated as a target to achieve clinical effectiveness with vancomycin. Through serum vancomycin concentration $>10 \mathrm{mg} / \mathrm{L}$ is the more practical method for monitoring of vancomycin effectiveness ${ }^{7}$. Using this drug in patients with AKI is a necessary evil as it is nephrotoxic. Vancomycin is predominantly cleared by renal excretion, making dosage adjustment during renal failure obligatory. The half-life of vancomycin is only 5-8 $\mathrm{h}$ in patients with normal renal function. It is extended up to about $180 \mathrm{~h}$ in patients with end-stage renal disease ${ }^{8}$. Volume of distribution of vancomycin is $0.4-1 \mathrm{~L} / \mathrm{kg}$, molecular weight 
$\sim 1450$ Da and protein binding from $10 \%$ to $50 \%$ (ref. $^{9}$ ). Vancomycin is not removed to a significant extent during hemodialysis with conventional low-flux hemodialysis membranes, such as those made of cuprophane and cellulose acetate ${ }^{10-12}$. However, recent studies have demonstrated enhanced removal of vancomycin during a single hemodialysis session with high-flux dialysis membranes, including high-flux polysulphone membrane ${ }^{13,14}$. Low-flux polysulphone membranes have smaller pore size resulting in lower clearance of middle molecular weight substances ${ }^{15}$. Several strategies have been proposed to appropriately dose vancomycin in high-flux hemodialysis. However, most studies have been performed in patients with chronic hemodialysis ${ }^{16-19}$. Critically ill patients are often haemodynamically unstable. They demonstrate alterations in drug pharmacokinetics due to multiorgan dysfunction and acute changes in volume state ${ }^{20}$. A substantial number of hemodialysis patients have residual renal function which may influence vancomycin clearance. Clearance of vancomycin during hemodialysis may be further affected by membrane specific and dialysis specific factors including surface area, permeability and clearance and adherence to the membrane. Blood flow and dialysate flow might also influence drug removal ${ }^{21}$. These conditions may lead to variability in vancomycin clearance during hemodialysis dosage regimens in a critical care setting.

Our aim was to determine the extent of vancomycin removal and vancomycin pharmacokinetics in septic patients with AKI using daily hemodialysis with polysulphone high-flux and low-flux membrane.

\section{MATERIAL AND METHODS}

This is an open, prospective cohort clinical study performed at two University Hospitals in the Czech Republic. The study protocol was approved by the Ethics Committees of both hospitals. Written informed consent was obtained from patients and two unrelated physicians.

\section{Subjects}

Nine critically ill adult patients with sepsis and AKI requiring extended daily dialysis on vancomycin therapy were included. Classification of acute kidney injury was made according to RIFLE criteria for AKI. All patients were in stage F of RIFLE criteria. They were followed up for two days after introduction to the study and all also concomitantly received fluoroquinolone and metronidazol.

\section{Study procedure}

Extended daily hemodialysis was performed in all patients with the batch dialysis system (AK $200 \mathrm{~S}$, GAMBRO, Sweden). Five patients received dialysis with low-flux polysulphone membrane PES-150 DL (Surface area $1.5 \mathrm{~m}^{2}$, NIPRO Corporation, Osaka, Japan), and four patients with high-flux polysulphone membrane F60S (Surface area $1.3 \mathrm{~m}^{2}$, Fresenius Medical Care, Germany). Blood flow rate $(\mathrm{Qb})$ was $200 \mathrm{~mL} / \mathrm{min}$ and dialysate flow rate $(\mathrm{Qd})$ was $500 \mathrm{~mL} / \mathrm{min}$. Patients underwent 6-h dialysis and the membrane was changed each dialysis session. Low-molecular heparin (nadroparine) was used as anticoagulation. EDD was performed through a double - lumen $14 \mathrm{~F}$ catheter inserted into the jugular or femoral vein.

Vancomycin was administered over the last hour of dialysis (Edicin, Sandoz, Lek Pharmaceuticals d.d., Ljubljana, Slovenia). Vancomycin was reconstituted with $100 \mathrm{~mL}$ 0.9\% sodium chloride and was administered using a controlled infusion pump into peripheral venous input for $1 \mathrm{~h}$. Vancomycin dose was adjusted according to vancomycin levels simulation using a pharmacokinetic programme MWPharm, version 3.60 (MEDIWARE, Groningen, the Netherlands). A vancomycin pre-hemodialysis concentration of $10-20 \mathrm{mg} / \mathrm{L}$ was chosen as a target concentration for vancomycin dosage adjustment. Blood samples were obtained before vancomycin administration, immediately after infusion, 1, $2 \mathrm{~h}$ after vancomycin administration and before each dialysis. Blood was collected into a $4.9 \mathrm{~mL}$ neutral tube (Sarstedt-Monovette) and blood samples were centrifuged. Serum vancomycin concentrations were determined using a fluorescence polarisation immunoassay method (ABBoTT AxSYM ${ }^{\mathrm{TM}}$, Abbott Laboratories, Diagnostics Division, Abbott Park, IL 60064 USA).

Vancomycin concentrations were analysed using the pharmacokinetic programme KINFIT (MWPharm, MEDIWARE version 3.60, Groningen, the Netherlands). The following pharmacokinetic parameters were calculated for each patient: volume of distribution (Vd), intradialytic and off dialysis total drug clearance $(\mathrm{Cl})$ and elimination half-life $\left(\mathrm{t}_{1 / 2}\right)$. Data are expressed as median and range. The elimination of vancomycin from blood during hemodialysis session was calculated from the following formula and expressed as \% concentration reduction:

$\%$ Vancomycin reduction $=\left[\left(\mathrm{C}_{\text {preHD }}-\mathrm{C}_{5 \mathrm{hHD}}\right) / \mathrm{C}_{\mathrm{preHD}}\right] \mathrm{x} 100$ where $\mathrm{C}_{\text {preHD }}=$ The concentration of vancomycin before hemodialysis, $\mathrm{C}_{5 \mathrm{hHD}}=$ the concentration of vancomycin before administration (last hour of hemodialysis)

\section{RESULTS}

The patients' and clinical characteristics are summarized in (Table 1). All patients suffered from severe sepsis. Bacterial agents were aerobic Gram - positive: Staphylococcus species, Staphylococcus haemolyticus, methicilin-resistant Staphylococcus aureus (MRSA, Enterococcus faecalis, Enterococcus faecium. Median Sequential Organ Failure Assessment (SOFA) score at inclusion was 15 (10 -16). All patients were in stage F according to RIFLE criteria of acute kidney injury. Median eGFR according to Cockroft-Gault was $0.4 \mathrm{~mL} / \mathrm{s}$ ( 0.18 to $0.5 \mathrm{~mL} / \mathrm{s})$. However, the eGFR values are overestimated because the calculation of eGFR is based on creatinine serum values which reflect muscle mass. Four patients were anuric. In five patients the urine output ranged between 19.0 - $166.7 \mathrm{~mL} / \mathrm{h}$. Due to fluid overload (more than $10 \%$ of patient's body 
weight) the loop diuretic agent furosemide was administered at a dose of $500-1000 \mathrm{mg} / 24 \mathrm{~h}$ in patients with preserved diuresis according to clinical practice carried out in ICUs. Median percentage of vancomycin removal by low-flux membrane dialysis was $17 \%$ (8-38\%). In one patient, $68 \%$ of vancomycin was removed by low-flux membrane dialysis on the second day of the study and intradialytic clearance was $30.94 \mathrm{~L} / \mathrm{h}$. We attribute these outlier values to the measurement error of vancomycin concentration $5^{\text {th }}$ hour of dialysis. Median percentage of vancomycin removal by high-flux membrane dialysis was $31 \%$ (13-43\%). When compared with low-flux membrane dialysis vancomycin clearance was only moderately higher in high-flux membrane dialysis in the first day of the study and about two-fold higher in the second day of the study (Table 2). An $\mathrm{AUC}_{0-24} / \mathrm{MIC}$ ratio $\geq 400$ was achieved in only 3 out of 9 patients on both study days. In patient number one, $\mathrm{AUC}_{0-24}$ on the second study day was not obtained due to measurement error of through vancomycin concentration (Table 3). Vancomycin serum concentrations above $10 \mathrm{mg} / \mathrm{L}$ before the second study dialysis were obtained in 7 out of 9 patients. The median vancomycin dose was $10.64 \mathrm{mg} / \mathrm{kg}(3.13-15.38 \mathrm{mg} / \mathrm{kg})$ in the first day and $10.99 \mathrm{mg} / \mathrm{kg}(3.13-15.38 \mathrm{mg} / \mathrm{kg})$ in the second study day. In eight of nine patients vancomycin had already been administered before inclusion in the study.

\section{DISCUSSION}

Vancomycin removal by high-flux polysulphone membrane dialysis was about two-fold higher than dialysis with low-flux polysulphone membrane. The daily vancomycin dosage was required in patients undergoing both high-flux and low-flux dialysis to achieve optimal through vancomycin concentrations.

Hemodialysis membranes, which are typically classified as low- or high-flux, vary in composition, surface area, water permeability, and the efficiency with which they remove urea and higher-molecular weight solutes. Low-flux membranes have smaller pores and lower ultrafiltration coefficients than high-flux membranes ${ }^{15}$. Vancomycin removal was about one half less during low-flux membrane hemodialysis compared with high-flux membrane dialysis in our study. Removal of vancomycin by high-flux dialysis membranes is significantly greater than by conventional membranes. A total vancomycin removal of $31 \%$ was observed in our study during high-flux membrane dialysis, compared with $25-50 \%$ of vancomycin removal found in other studies ${ }^{13,22}$. Variability in vancomycin removal in both high-flux and low-flux membrane dialysis was found in our study as described in other studies ${ }^{23}$. Despite different vancomycin removal in low- and high-flux dialysis, daily vancomycin dosing in both type of dialysis was required to keep optimal vancomycin through levels. However due to limited number of patients studied and changing vancomycin dosing regimen it was impossible to discriminate between vancomycin dosing requirements in both dialysis procedures. Contemporary high-flux membranes eliminate vancomycin with an estimated vancomycin clearance of 43.3-120 mL/min (ref. ${ }^{24}$ ). Intradialytic clearance of vancomycin varied between the two study days. We observed about 2-fold higher vancomycin intradialytic clearance with high-flux membrane compared to low-flux membrane on the second day. However the difference between the dialysis was only moderate on the first day.

Vancomycin dose was administered over the last hour of dialysis in our patients. Although the use of vancomy-

Table 1. Patients' demographic and clinical characteristics.

\begin{tabular}{ccccccc}
\hline Patient & Sex & $\begin{array}{c}\text { Age } \\
\text { (years) }\end{array}$ & $\begin{array}{c}\text { Weight } \\
(\mathbf{k g})\end{array}$ & $\begin{array}{l}\text { SOFA } \\
\text { score }\end{array}$ & Pathogen/MIC & Diagnosis \\
\hline & & & & \multicolumn{2}{c}{ Low-flux membrane } & \\
\hline $\mathbf{1}$ & $\mathrm{M}$ & 71 & 88 & 11 & Ent. faecium/0,5 & Peritonitis, MODS \\
$\mathbf{2}$ & $\mathrm{M}$ & 56 & 80 & 16 & Staph. species/1.0 & Pneumonia \\
$\mathbf{3}$ & $\mathrm{M}$ & 71 & 77 & 15 & Staph. species/1,0 & Endocarditis \\
$\mathbf{4}$ & $\mathrm{M}$ & 63 & 94 & 10 & Ent. faecalis 1,0 & Urosepsis, Enterocolitis \\
$\mathbf{5}$ & $\mathrm{M}$ & 38 & 80 & 12 & Staph. haemolyticus/0,25 & Meningitis \\
\hline & & & & High-flux membrane & Endocarditis \\
\hline $\mathbf{6}$ & $\mathrm{M}$ & 72 & 97 & 13 & Staph. species/1,0 & Peritonitis \\
$\mathbf{7}$ & $\mathrm{M}$ & 69 & 91 & 15 & Ent. faecalis/1,0 & Meningitis \\
$\mathbf{9}$ & $\mathrm{M}$ & 70 & 67 & 15 & MRSA/0,5 & Mediastinitis \\
\hline
\end{tabular}

SOFA = Sequential Organ Failure Assessment, M = male, MRSA = methicilin-resistant Staphylococcus aureus, MIC - minimum inhibitory concentration 
Table 2. Pharmacokinetic parameters of vancomycin.

\begin{tabular}{ccccc}
\hline Vancomycin & Day 1 & Day 1 & Day 2 & Day 2 \\
\hline Membrane & Low-flux membrane & High-flux membrane & Low-flux membrane & High-flux membrane \\
$\mathrm{Vd}(1 / \mathrm{kg})$ & $0.38(0.21-0.97)$ & $0.43(0.38-0.81)$ & $0.35(0.28-0.55)$ & $0.50(0.19-0.56)$ \\
$\mathrm{Cl}_{\text {off }}(1 / \mathrm{h})$ & $1.54(0.40-1.69)$ & $0.82(054-5.91)$ & $0.51(0.41-1.95)$ & $0.50(0.31-1.64)$ \\
$\mathrm{Cl}_{\mathrm{HD}}(1 / \mathrm{h})$ & $2.48(0.53-5.68)$ & $3.01(2.34-3.5)$ & $1.74(0.75-30.94)$ & $3.62(1.37-5.07)$ \\
$\mathrm{T}_{1 / 2}(\mathrm{~h})$ & $18.82(16.24-51.01)$ & $28.41(9.19-32.04)$ & $35.35(14.92-49.7)$ & $39.08(22.87-59.35)$ \\
$\mathrm{T}_{1 / 2 \mathrm{HD}}(\mathrm{h})$ & $18.08(8.49-42.55)$ & $11.18(9.39-12.49)$ & $16.59(3.07-38.08)$ & $7.47(6.19-24.03)$ \\
\hline
\end{tabular}

$\mathrm{Vd}$ - volume of distribution, $\mathrm{Cl}_{\text {off }}$ - vancomycin clearance off dialysis, $\mathrm{Cl}_{\mathrm{HD}}$ - vancomycin clearance during dialysis, $\mathrm{T}_{1 / 2}-$ vancomycin half-life off dialysis, $\mathrm{T}_{1 / 2 \mathrm{HD}}$ - vancomycin half-life during dialysis

Table 3. PK/PD vancomycin parameters of individual patients.

\begin{tabular}{|c|c|c|c|c|c|c|c|c|c|c|}
\hline 苛 & 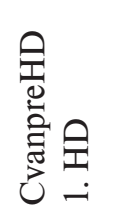 & 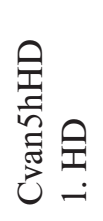 & 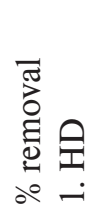 & 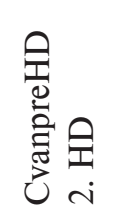 & 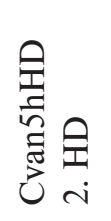 & 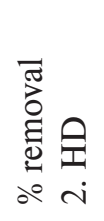 & 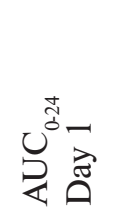 & 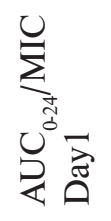 & 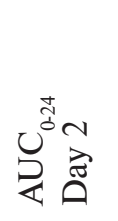 & 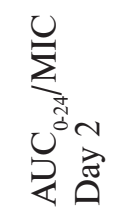 \\
\hline \multicolumn{11}{|c|}{ Low-flux membrane dialysis } \\
\hline 1 & 7.19 & 4.78 & 33 & 7.29 & 2.36 & 68 & 181.9 & 363.8 & - & - \\
\hline 2 & 13.28 & 9.75 & 27 & 11.99 & 9.73 & 19 & 338.4 & 338.4 & 305.2 & 305.2 \\
\hline 3 & 8.21 & 7.17 & 13 & 11.69 & 7.25 & 38 & 338.8 & 338.8 & 345.1 & 345.1 \\
\hline 4 & 13.7 & 11.31 & 17 & 12.07 & 11.02 & 9 & 387.9 & 387.9 & 343.1 & 343.1 \\
\hline 5 & 7.67 & 7.07 & 8 & 8.1 & 6.87 & 15 & 242.9 & 969.8 & 208.5 & 834 \\
\hline \multicolumn{11}{|c|}{ High-flux membrane dialysis } \\
\hline 6 & 0.0 & 0.0 & - & 12.58 & 8.27 & 34 & 258.6 & 258.6 & 318.1 & 318.1 \\
\hline 7 & 18.35 & 13.98 & 24 & 21.0 & 18.18 & 13 & 589.2 & 589.2 & 596.4 & 596.4 \\
\hline 8 & 15.81 & 10.93 & 31 & 22.11 & 12.63 & 43 & 406.3 & 812.6 & 514.9 & 1029.8 \\
\hline 9 & 26.52 & 19.45 & 27 & 26.64 & 15.85 & 41 & 746.9 & 373.5 & 623.7 & 311.9 \\
\hline
\end{tabular}

PK - pharmacokinetics, PD-pharmacodynamics, CvanpreHD - vancomycin serum concentration before dialysis, Cvan5hHD - vancomycin serum concentration $5^{\text {th }}$ hour of dialysis (before vancomycin administration)

cin during the last hour of dialysis may lead to a certain loss of drug, this strategy is more practical and the loss of vancomycin may be compensated for by administration of higher vancomycin doses based on therapeutic drug monitoring ${ }^{22}$. The rebound of vancomycin serum concentrations occurs following dialysis with highly permeable membranes. The post-redistribution phase averaged six hours, but ranged between 1 to $12 \mathrm{~h}$ (ref. ${ }^{24}$ ). Thus, the absolute vancomycin removal during dialysis may be overestimated and estimation of vancomycin serum concentrations should be based upon concentrations drawn before dialysis session.

The existing dosing for patients with chronic renal failure undergoing intermittent dialysis may not be applicable to septic patients with AKI treated with EDD (ref. ${ }^{25,19}$ ).
Septic patients are usually highly catabolic and often need a larger dose of renal replacement therapy ${ }^{25}$. Patients with AKI appear to eliminate vancomycin differently from patients with chronic renal failure. In patients with acute oliguric renal failure, substantial nonrenal clearance of vancomycin appears to occur initially ${ }^{26}$. A number of hemodialysis patients have residual renal function, which may influence vancomycin clearance. Thus vancomycin concentrations may be lower in patients with intrinsic clearance if one uses dosing guidelines for anuric patients. Clinicians need to be aware of patients' residual renal function and appropriately adjust vancomycin doses. This especially concerns septic patients with AKI and variable renal function. Further, sepsis can lead to the development of endothelial damage and increase capillary 
permeability, which cause displacement of fluids from the vasculatury into the interstitium. The volume of distribution of hydrophilic drugs in critically ill patients with AKI can differ substantially from that reported in pharmacokinetic studies on healthy individuals ${ }^{6}$. However, we and other studies have observed a similar volume of distribution in vancomycin compared with healthy volunteers ${ }^{8,23}$

Due to high pharmacokinetic variability in acute septic patients with $\mathrm{AKI}$, we recommend daily monitoring of vancomycin concentrations before the next dialysis. During the 3-6 h following high-flux dialysis, blood concentrations of vancomycin rebound by $16-36 \%$, reflecting a redistribution phase. During high-flux dialysis, vancomycin elimination from the central compartment exceeds the rate of redistribution from tissue and blood levels fall. Following cessation of dialysis, blood levels rise as vancomycin equilibrates from tissue to blood. Consequently, estimates of vancomycin removal based on an immediate post-dialysis serum levels will overestimate its dialytic clearance $^{27,28}$. Thus, it might also be appropriate to monitor vancomycin serum concentration 6-12 h after dialysis.

An AUC/MIC ratio $\geq 400$ has been advocated as a target to achieve clinical effectiveness with vancomycin therapy ${ }^{7}$. However, because it can be difficult in the clinical setting to obtain multiple serum vancomycin concentrations to determine AUC and subsequently calculate AUC/MIC, through serum concentration monitoring, which can be used as a surrogate marker for AUC, is recommended as the most accurate and practical method for vancomycin monitoring. Through vancomycin serum concentrations maintained above $10 \mathrm{mg} / \mathrm{L}$ are recommended (ref.7). Despite $78 \%$ of our patients ( 7 out of 9 ) having vancomycin pre-dialysis serum concentrations above 10 $\mathrm{mg} / \mathrm{L}$ only $33 \%$ patients ( 3 out of 9 ) achieved vancomycin AUC/MIC $\geq 400$ in contrast to previously published study $^{29}$. The desired AUC/MIC ratio was achieved almost only in patients with vancomycin $\mathrm{MIC}<1.0 \mathrm{mg} / \mathrm{L}$. In patients with $\mathrm{MIC} \geq 1.0 \mathrm{mg} / \mathrm{L}$ higher dosing will be required. Vancomycin-induced nephrotoxicity has been related to drug plasma concentrations ${ }^{9}$. Nephrotoxicity is a concern for those hemodialysis patients who have some residual renal function and mainly for those patients with AKI. A target AUC/MIC of $\geq 400$ is not achievable with conventional dosing methods if the pathogen vancomycin $\mathrm{MIC}$ is $\geq 2 \mathrm{mg} / \mathrm{L}$. Achievement of this ratio would lead to undesirable vancomycin toxicity.

\section{CONCLUSION}

Both high-flux and low-flux membrane dialysis remove considerable amounts of vancomycin in critically ill septic patients with AKI. The extent of vancomycin removal varies in both types of dialysis. Despite differences in vancomycin removal between low-flux and high-flux dialysis, application of vancomycin after each dialysis is required to maintain therapeutic concentrations. Antibiotic underdosing is undesirable in these patients. Daily vancomycin serum concentration monitoring before dialysis is recom- mended with dosage adjustment based on measured vancomycin concentrations.

\section{ACKNOWLEDGEMENT}

The authors thank all of the doctors and nurses of all the intensive care units that contributed to this study.

This project was supported by grant IGA MZCR NS 10309-3/2009.

\section{CONFLICT OF INTEREST STATEMENT}

Author's conflict of interest disclosure: The authors stated that there are no conflicts of interest regarding the publication of this article.

\section{REFERENCES}

1. Rangel-Frausto MS, Pittet D, Costigan M, Hwang T, Davis CS, Wenzel RP.The natural history of the systemic inflammatory response syndrome (SIRS). A prospective study. JAMA 1995;273:117-23.

2. Langenberg C, Bellomo R, May C, Wan L, Egi M, Morgera S. Renal blood flow in sepsis. Crit Care 2005;9:R363-74.

3. Uchino S, Bellomo R, Morimatsu H, Morgera S, Schetz M, Tan I, Bouman C, Macedo E, Gibney N, Tolwani A, Oudemans-van Straaten $\mathrm{H}$, Ronco C, Kellum JA. Continuous renal replacement therapy: a worldwide practice survey. The beginning and ending supportive therapy for the kidney (B.E.S.T. kidney) investigators. Intensive Care Med 2007;33:1563-70.

4. Rabindranath K, Adams J, Macleod AM, Muirhead N. Intermittent versus continuous renal replacement therapy for acute renal failure in adults. Cochrane Database Syst Rev 2007;18:CD003773.

5. Bellomo R, Palevsky PM, Bagshaw SM, Gibney N, McAlister FA, Honore PM, Joannes-Boyau O, Prowle J, Haase M, Cruz DN, Ronco C. Recent trials in critical care nephrology. Contrib Nephrol 2010;165:299-309.

6. McKenzie C.Antibiotic dosing in critical illness. J Antimicrob Chemother 2011;66 Suppl 2:ii25-31.

7. Rybak MJ, Lomaestro BM, Rotschafer JC, Moellering R Jr, Craig W, Billeter M, Dalovisio JR, Levine DP. Therapeutic monitoring of vancomycin in adults summary of consensus recommendations from the American Society of Health-System Pharmacists, the Infectious Diseases Society of America, and the Society of Infectious Diseases Pharmacists. Am J Health-Syst Pharm 2009;66:82-98.

8. Matzke GR, McGory RW, Halstenson CE, Keane WF. Pharmacokinetics of vancomycin in patients with various degrees of renal function. Antimicrob Agents Chemother 1984;25:433-7.

9. Rybak MJ. The Pharmacokinetic and Pharmacodynamic Properties of Vancomycin. Clin Inf Dis 2006;42:S35-9.

10. Cunha BA, Quintiliani R, Deglin JM, Izard MW, Nightingale $\mathrm{CH}$. Pharmacokinetics of vancomycin in anuria. Rev Infect Dis http:// www.ncbi.nlm.nih.gov/ 1981;3 suppl:S269-72.

11. Moellering RC Jr, Krogstad DJ, Greenblatt DJ. Vancomycin therapy in patients with impaired renal function: a nomogram for dosage. Ann Intern Med 1981;94:343-6.

12. Lindholm DD, Murray JS. Persistence of vancomycin in the blood during renal failure and its treatment by hemodialysis. N Engl J Med 1966;274:1047-51.

13. Foote EF, Dreitlein WB, Steward CA, Kapoian T, Walker JA, Sherman RA. Pharmacokinetics of vancomycin when administered during high flux hemodialysis. Clin Nephrolhttp://www.ncbi.nlm.nih.gov/ 1998;50:51-5.

14. Touchette MA, Patel RV, Anandan JV, Dumler F, Zarowitz BJ. Vancomycin removal by high-flux polysulfone hemodialysis membranes in critically ill patients with end-stage renal disease. Am J Kidney Dis 1995;26:469-74. 
15. Stamatakis MK, Schreiber JM, Slain D, Gunel E. Vancomycin administration during dialysis with low-flux polysulfone membranes: traditional versus a supplemental dosage regimen. Am J Health Syst Pharm 2003;60:1564-8.

16. Barth RH, DeVincenzo N. Use of vancomycin in high-flux hemodialysis: experience with 130 courses of therapy. Kidney Int 1996;50:929 36.

17. Keller F, Hörstensmeyer C, Looby M, Borner K, Pommer W, Erdmann K, Giehl M. Vancomycin dosing in haemodialysis patients and Bayesian estimate of individual pharmacokinetic parameters. Int J Artif Organs 1994;17:19-26.

18. Zoer J, Schrander-van der Meer AM, van Dorp WT. Dosage recommendation of vancomycin during haemodialysis with highly permeable membranes. Pharm World Sci 1997;19:191-6.

19. Ariano RE, Fine A, Sitar DS, Rexrode S, Zelenitsky SA. Adequacy of a vancomycin dosing regimen in patients receiving high-flux hemodialysis. Am J Kidney Dis 2005;46:681-7.

20. Bogard KN, Peterson NT, Plumb TJ, Erwin MW, Fuller PD, Olsen KM. Antibiotic dosing during sustained low-efficiency dialysis: special considerations in adult critically ill patients. Crit Care Med 2011;39:560-70.

21. Lanese DM, Alfrey PS, Molitoris BA. Markedly increased clearance of vancomycin during hemodialysis using polysulfone dialyzers. Kidney Int 1989;35:1409-12.
22. Mason NA, Neudeck BL, Welage LS, Patel JA, Swartz RD. Comparison of 3 vancomycin dosage regimens during hemodialysis with cellulose triacetate dialyzers: post-dialysis versus intradialytic administration. Clin Nephrol 2003;60:96-104.

23. Kielstein JT, Czock D, Schöpke T, Hafer C, Bode-Böger SM, Kuse E, Keller F, Fliser D. Pharmacokinetics and total elimination of meropenem and vancomycin in intensive care unit patients undergoing extended daily dialysis. Crit Care Med 2006;34:51-6.

24. Vandecasteele SJ, De Vriese AS. Recent changes in vancomycin use in renal failure. Kidney Int 2010;77:760-4

25. Panais R, Hirsch DJ, Dipchand C, Storsley L, Finkle SN. A protocolized approach to vancomycin dosing in conventional hemodialysis. J Nephrol 2010;23:569-74.

26. Macias WL, Mueller BA, Scarim SK. Vancomycin pharmacokinetics in acute renal failure: preservation of nonrenal clearance. Clin Pharmacol Ther 1991;50:688-94.

27. Launay-Vacher V, Izzedine H, Mercadal L, Deray G. Clinical review: use of vancomycin in haemodialysis patients. Crit Care 2002;6:313-16.

28. Pollard TA, Lampasona V, Akkerman S, Tom K, Hooks MA, Mullins RE, Maroni BJ. Vancomycin redistribution: dosing recommendations following high-flux hemodialysis. Kidney Int 1994;45:232-7.

29. Zahálková J, Strojil J, Petejová N, Urbánek K, Grundmann M, Kacírová I. Dávkovaní vankomycinu při kontinuální náhradě funkce ledvin. Klin Farmakol Farm 2011;25:116-21. 